\section{EDUCAÇÃO, CURRÍCULO E MEIO AMBIENTE: Fábrica ou Ateliê de Subjetividades?}

\author{
EDUCATION, CURRICULUM AND ENVIRONMENT: Factory or Workshop of Subjectivities?
}

Maristela Barenco Corrêa de Mello'

Resumo: Em um cenário de crise socioambiental, marcado por uma insuficiência epistemológica de conceitos e de sentidos potentes em Educação Ambiental - que estejam atentos em relação à reprodução de uma lógica hegemônica que está na base da própria crise -, e que sejam capazes de inventar e produzir percursos e perspectivas outras que não mais legitimem estes itinerários, este artigo pretende trazer a temática da Subjetividade, que atravessa o discurso sobre Meio Ambiente, Educação Ambiental e Currículo, mais como ausência do que presença, ora configurando em modos de subjetivação, na perspectiva de uma fábrica; ora configurando em modos de singularização, na perspectiva de um ateliê. O presente ensaio parte de uma tese de doutoramento e de um diálogo com Félix Guattari e Suely Rolnik, e se compromete com o campo dos processos de educação ambiental que pensam e trabalham os modos de singularização da subjetividade. Para testemunhar tal percurso, enquanto práxis, a autora traz um fragmento de uma experiência vivida com o grupo de jovens Filhos da Terra, idealizado por um coletivo a qual fez parte, em uma organização não-governamental de Direitos Humanos, cujo objetivo era fortalecer a perspectiva da Arte-Cidadania e Ecologia, com jovens de comunidades pobres.

Palavra-chave: Epistemologias. Processos de Subjetivação. Modos de Singularização. Projeto Socioambiental.
Abstratc: In a scenario marked by an epistemological insufficiency of powerful concepts and meanings in Environmental Education - who are aware of the reproduction of a hegemonic logic that is the basis of the socio-environmental crisis itself -, and that are capable of inventing and producing other paths and perspectives that no longer legitimize these itineraries, this article intends to bring the theme of Subjectivity, which crosses the discourse on Environment, Environmental Education and Curriculum, more like absence than presence, sometimes configuring in modes of subjectivation, in the perspective of a factory; sometimes configuring in modes of singularization, from the perspective of an atelier. The present essay is based on a doctoral thesis and a dialogue with Félix Guattari and Suely Rolnik, and is committed to the field of environmental education processes that think and work the modes of singularization of subjectivity. To witness this course, as a praxis, the author brings a fragment of an experience lived with the group of young children of the Earth, idealized by a collective that was part of a non-governmental human rights organization whose objective was to strengthen the perspective of Art-Citizenship and Ecology, with young people from poor communities.

Keywords: Epistemology. Subjectivation Processes. Modes of Singularization. Social and Environmental Projects.

\section{INTRODUÇÃO}

As últimas décadas testemunham a aceleração e a efetivação de um processo postulado a partir da década de 70 com a consolidação do movimento ambientalista: a irrefutabilidade de uma crise socioambiental em escala planetária. Neste contexto mundial, o Meio Ambiente tem emergido no cenário educacional como uma urgência e um imperativo, tendo a sua discussão sustentada por documentos básicos ${ }^{2}$ mas, sobretudo, por diretrizes políticas, propostas político-pedagógicas e metodológicas. Tal tendência ganha força em um contexto cultural onde se atribui à Educação a responsabilidade por grande

\footnotetext{
${ }^{1}$ Professora Adjunta do Departamento de Ciências Humanas do Infes/UFF e Professora dos Programas de Pós Graduação em Ensino (PPGEn/UFF) e do Programa de Pós-Graduação em Meio Ambiente (PPGMA/UERJ). E-mail: < stelabarenco@oi.com.br>. ORCID: <http://orcid.org/0000-0003-0634-7112>.

${ }^{2}$ Refiro-me, sobretudo, à Lei 9.795, de 27 de abril de 1999, que institui a Polícia Nacional de Educação Ambiental, ao documento A Carta da Terra e o Tratado de Educação Ambiental para Sociedades Sustentáveis e Responsabilidade Global, ambos idealizados a partir da Rio-92 ou Cúpula da Terra, nomes dados à Conferência das Nações Unidas sobre o Meio Ambiente e o Desenvolvimento, ocorrida no Rio de Janeiro em 1992.
} 
parte das transformações sociais e políticas. Não se pode mais falar em Educação sem concebê-la também como Educação Ambiental.

Contudo, por se constituir uma área do conhecimento ainda muito recente e pouco refletida em suas bases conceituais e em suas premissas paradigmáticas, epistemológicas, filosóficas e políticopedagógicas, a Educação Ambiental muitas vezes tem despontado, nas práticas escolares, de forma não crítica, ou como eixo transversal imperceptível, ou ainda como especialidade disciplinar, em forma de projetos pontuais no ano letivo, geralmente em perspectivas normativas e mecanicistas, como trabalho temático e desarticulado, enfim, sem uma clareza e uma reflexão prévias, imprescindíveis. Grün (2006, pp.54-56) postula que as propostas de Educação Ambiental inauguram discursos que se pautam nos mesmos princípios que pretendem criticar, ao evidenciar que a "cisão cartesiana entre a natureza e cultura é a base da educação moderna e constitui-se em um dos principais entraves para a promoção de uma educação ambiental realmente profícua" e "não raro, propostas de educação ambiental são apanhadas na fina e sofisticada malha discursiva do cartesianismo" (GRÜN, 2006, p. 45). No dizer de Loureiro (2004, p. 20), "Há, de fato, no campo do debate ambiental um senso comum generalizado e pouco reflexivo sobre conceitos que, ao serem apropriados indistintamente e sem rigor teórico, ocasionam a perda de competência para se estabelecerem com clareza o que se quer com e o que é o fazer educativo ecológico, cidadão e crítico".

O que nos interessa, neste contexto, são conceitos próprios e com sentidos potentes, com os quais nos sintamos capazes de inventar e produzir percursos e perspectivas outras que não mais legitimem estes itinerários. Para isso pretendo trazer aqui uma temática que vem sendo produzida mais como ausência do que como presença em relação ao Meio Ambiente, à Educação Ambiental e ao Currículo - a saber, a Subjetividade -, mas que se encontra sempre como matéria-prima dos processos sociais, ora configurando modos de subjetivação, na perspectiva de uma fábrica, ora configurando modos de singularização, na perspectiva de um ateliê.

O que significa pensar uma Educação Ambiental e em um currículo subjacente, que estejam atentos para a importância do resgate da Subjetividade, esta dimensão que foi recalcada a partir do cartesianismo? O que significa pensar em uma Educação Ambiental comprometida com os modos de singularização ${ }^{3}$ do sujeito? Existe alguma experiência concreta de trabalho nesta linha, que conjugue Educação Ambiental com produção de singularidades, na perspectiva de um ateliê?

O objetivo do presente ensaio é compartilhar reflexões sobre as questões acima, a partir de Guattari e Rolnik, que fizeram parte do processo de doutoramento da autora, e ainda não foram socializadas, e que ganham pertinência no atual contexto político e educacional brasileiro. Para que tal reflexão se revele práxis, trazemos um fragmento apenas de uma experiência de um projeto social, na tentativa de compreender o que significa pensar na educação ambiental comprometida com modos de singularização e com uma formação voltada para o ateliê.

Contextualizando o projeto a partir do qual traremos um fragmento, ele se chama Filhos da Terra, e não se encontra ativo coletivamente, mas trouxe como contribuição a formação de jovens artistas, moradores em comunidades de Petrópolis, que hoje são psicólogos, bailarinos, artistas circenses e de teatro, escultores e pintores. O projeto consistia na confecção e criação de cartões ecoartesanais, elaborados apenas com elementos encontrados na natureza. Idealizado pelo Centro de Defesa dos Direitos Humanos de Petrópolis, onde a autora era coordenadora pedagógica, o grupo tornou-se ponto de cultura do Ministério da Cultura, fez exposições renomadas, ministrou oficinas ecoartesanais pelo Brasil e transformou arte e reflexão em inclusão e subsistência. Sua descrição e metodologia encontramse sistematizadas e publicadas ${ }^{4}$. A iniciativa piloto aconteceu durante aproximadamente quinze anos, a

\footnotetext{
3 Conceito de Guattari e Rolnik (1986, p. 17;47), que diz respeito a um processo contra-hegemônico à interiorização dos valores capitalísticos, entendidos como processos de subjetivação. Significa uma recusa dos modos hegemônicos, tendo em vista a construção de uma diversidade de modos, que passam pela sensibilidade, pela relação com o outro; a produção; o consumo; a criatividade. Refere-se a uma subjetividade singular.

${ }^{4}$ MELLO, Maristela Barenco Corrêa de \& CDDH Petrópolis. Projeto Florescer: Arte-Educação, Cidadania e Ecologia. Uma Metodologia para trabalhar com jovens. Petrópolis: Centro de Defesa dos Direitos Humanos de Petrópolis, 2010. 95 p.
} 
partir do ano 2000, e tinha um diferencial em relação aos projetos sociais que trabalhavam com adolescência e juventude. A saber: não se constituir um projeto de profissionalização voltado para o mercado de trabalho, mas sensibilizar os jovens para buscarem outras visões de mundo e formas de se relacionar com todas as dimensões da vida, de maneira sistêmica, includente, solidária, ecológica e cooperativa, acreditando na possibilidade de transformação do mundo; desenvolver-se através de oficinas - alinhadas em sua forma, linguagem e conteúdos -, como espaços privilegiados de uma construção coletiva do saber, onde os jovens eram sujeitos do conhecimento; apostar nos processos artísticos como aqueles que sensibilizam os jovens a (re)inventarem a si mesmos e ao mundo; prezar por uma metodologia participativa e reflexiva, levando-se sempre em conta o lúdico e o artístico; comprometimento com uma arte inspirada nas narrativas histórico-culturais de versão popular, dos excluídos e dos que tiveram suas epistemes produzidas como ausências.

A metodologia do presente ensaio é conduzir o pensamento sobre a Subjetividade, como matériaprima da produção de sujeitos e micropolítica, através de um percurso com três estações: a subjetividade como fábrica em seus processos de subjetivação; a subjetividade como ateliê em seus processos de singularização; a experiência concreta de um projeto social capaz de articular educação ambiental, currículo e modos de singularização.

\section{A SUBJETIVIDADE COMO MATÉRIA-PRIMA DOS PROCESSOS SOCIAIS E MICROPOLÍTICA}

Se os marxistas e progressistas de todo tipo não compreendem a questão da subjetividade, porque se entupiram de dogmatismo teórico, isso em compensação não aconteceu com as forças sociais que administram o capitalismo hoje.

Elas entenderam que a produção de subjetividade talvez seja mais importante que qualquer outro tipo de produção, mais essencial até que o petróleo e as energias

Félix Guattari

A minha trajetória como educadora social, por mais de duas décadas, tornou-me testemunha, não poucas vezes, do desmoronamento de inúmeras iniciativas comunitárias, sociais, organizativas e políticas que, ao longo dos anos, veio buscando implementar práticas socioambientais e sustentáveis, de grande relevância, mas que se viram - sempre de forma surpreendente! -, suspensas e interrompidas por questões da ordem de uma subjetividade: formas de organização, conflitos interpessoais, limites psicológicos, disputas pelo poder, predominância de interesses pessoais sobre os interesses coletivos, dentre outras formas - aspectos de uma subjetividade que perpassa o nível de uma micropolítica ${ }^{5}$, que vem sendo subestimada em todos os tempos de nossa formação política, e que é tão determinante no êxito e fracasso de algumas experiências, quanto às deliberações macrossociais e macropolíticas. Inúmeras vezes os próprios educadores sociais caímos no risco de nos sentirmos imunes diante da premência de pensarmos e nos pensarmos dentro deste processo político cotidiano. Em outras palavras, no caso do Meio Ambiente, estamos nos referindo aos processos sempre contraditórios e desafiantes de querermos construir uma cultura capaz de superar o antropocentrismo e afirmar a legitimidade de todas as formas de vida, mas, ao buscarmos ensaiar isso, vermo-nos reféns de uma lógica que reforça os modos antropocêntricos e que colocam o Meio Ambiente como recurso a ser explorado.

De um modo geral, raramente nos damos conta, como intelectuais, políticos ou educadores, o quanto somos capturados pelos mecanismos da mesma lógica que criticamos e queremos superar. E o

\footnotetext{
${ }^{5}$ Constitui uma categoria de análise, proposta por Guattari e Rolnik (1986), que se refere a uma cartografia dos percursos do desejo, ou analítica dos percursos do poder, do inconsciente, do desejo, em um nível considerado molecular, cotidiano.
} 
quanto fazemos a manutenção destes lógicas em nossas formas de ensinar e educar. Guattari e Rolnik (1986) nos chamam a atenção para estes desafios, de forma dura e realista:

Basta tirar os olhos, um instante, das representações da política que a mídia proporciona e examinar o que se passa no teatro dos afetos - que não querem saber de nada, que não fazem senão seguir os gestos, o movimento dos lábios, as caretas, a falta de graça dos corpos - basta isso para descobrir que, na maior parte do tempo, os campeões da liberdade são tão desprezíveis quanto os outros, os defensores do conservadorismo. E quando essa ronda começa a funcionar ao nível mais baixo, grass-root, rasteiro, é que entramos num processo possível de validação das práticas sociais moleculares (GUATTARI; ROLNIK, 1986, p. 134).

Esta constatação nos remete à Freire (1984), em sua Pedagogia do Oprimido, onde o autor descreve, com maestria, o fenômeno pelo qual passam os oprimidos, de "hospedarem" dentro de si a dimensão lógica dos opressores. Daí postula a importância de uma pedagogia que "restaure a intersubjetividade" (FREIRE, 1984, p. 43). Nesta linha interpretativa, nossos modos de pensar, como agentes sociais, educadores e ou políticos ainda não representam certa ruptura epistemológica e ideológica com a normatividade e com a discursividade a qual queremos desconstruir:

[...] o inimigo não está só nos imperialismos dominantes. Ele está também em nossos próprios aliados, em nós mesmos, nessa insistente reencarnação dos modelos dominantes, que encontramos não só nos partidos mais queridos ou nos líderes que nos defendem da melhor maneira possível, mas também em nossas próprias atitudes, nas mais diversas ocasiões (GUATTARI; ROLNIK, 1986, p. 48).

Por isso precisamos, mais do que em outros tempos, questionarmo-nos sobre o que o campo dos processos de educação ambiental tem dito, pensado e refletido sobre o lugar e a importância da subjetividade (dimensões do desejo, do inconsciente e da vida como drama), nos processos políticopedagógicos que objetivam transformar a realidade e frente às práticas hegemônicas de subjetivação. É sobre isso que se debruça este breve estudo. A Subjetividade que ora se apresenta como temática/problemática, não diz respeito a uma abordagem individualista e terapêutica, mas a uma concepção política. Sim, subjetividade como dimensão micropolítica (Guattari e Rolnik, 1986), determinando um projeto político mais amplo.

Pensar esta problemática implica, também, pensar, de forma epistemológica e crítica, os currículos e os projetos que vão fazer parte das políticas e práticas pedagógicas de nossas Escolas.

\section{A Subjetividade como Fábrica em seus Processos de Produção}

Guattari e Rolnik (1986) conjugam capitalismo e subjetividade de forma inseparável. Concebem a subjetividade como a matéria-prima de todos os processos que culminam em um modo de vida hegemônico. E afirmam que o capitalismo entendeu bem este processo que as forças socialistas ainda subestimam. Enquanto o capital se ocupa da sujeição econômica através de uma "mais-valia econômica", a cultura se ocupa da sujeição subjetiva através de uma "mais-valia de poder" (GUATTARI; ROLNIK, 1986, p. 32).

Para os autores, qualquer mudança na estrutura macropolítica terá que levar em conta os processos de subjetivação, já que esta faz, do sistema do capital, não apenas um sistema de produção e de economia, mas um modo de ser, de pensar o mundo e todas as suas inter-relações.

Diferentemente do que podemos supor e imaginar, a subjetividade não é uma propriedade de um indivíduo, fechado em si mesmo, nem o somatório de todas as individualidades, nem a atualização de uma essência metafísica. Embora tenhamos corpos e nomes próprios e estejamos na posição de consumidores de subjetividade, somos atravessados por uma multiplicidade de condicionamentos, que nos modelizam não ao nível de uma representação, de natureza ideológica, mas através de um processo invisível, subliminar, inconsciente, que invade o nível dos sonhos, das fantasias, dos apaixonamentos, enfim, em relação a uma "economia coletiva do desejo". É um processo sutil que se encarna na vida e não fica apena ao nível das idéias. Há uma íntima ligação entre produção social, material e semiótica 
(produção de sentido). Tais processos podem, em algumas circunstâncias, se "individuar", mas são processos eminentemente sociais, que tomam formas particulares.

Por isso, a subjetividade, como "agenciamentos coletivos de enunciação" (GUATTARI; ROLNIK, 1986, p. 31), para estes autores, constitui o resultado de um processo de produção, fabricação, modelação no registro social e no inconsciente, que se situa hoje em escala planetária.

Com Deleuze, Guattari identifica um "ambiente maquínico" de construção de imagens-referência, que se propagam institucionalmente através de efeitos discursivos, que produzem instâncias como a "culpabilização", a "segregação" e a "infantilização" dos indivíduos.

A "culpabilização" constitui uma estratégia de todos os sistemas de modelização das subjetividades e já foi trabalhada por Foucault (1989). Na culpa não há necessariamente alguém objetivo que nos culpe. E Guattari caracteriza bem este processo: "há algo de nós mesmos, em nós mesmos e que nós mesmos reproduzimos. Instâncias do superego e instâncias de inibição" (GUATTARI; ROLNIK, 1986, p. 41). O culpado é alguém que se vê desprovido da potência de intervir e aceita a sua condição, por sentirse responsável pela violência que o atinge. $O$ racismo ambiental tem muito a refletir sobre esta instância.

A "segregação" está diretamente vinculada à "culpabilização" e é um processo que se dá através da introjeção de "sistemas de hierarquia inconsciente, sistemas de escalas de valor e sistemas de disciplinarização", que legitimam desigualdades e diferentes lugares sociais. As conseqüências aqui são compreendidas como causas.

Por fim, a "infantilização" seria uma das instâncias mais importantes e se manifesta através da forma como "pensam por nós, organizam por nós a produção e a vida social” (GUATTARI; ROLNIK, 1986, p. 41). Guattari descreve alguns tipos sociais infantilizados como os loucos, as mulheres, certos setores sociais ou mesmo comportamentos dissidentes, que carecem sempre da relação de dependência ou mediação do Estado.

Inseridos nestes processos de modelização de subjetividades, emerge a micropolítica, como analítica das cartografias do desejo e das formações do inconsciente no campo social, evidenciando que as realidades são atravessadas por diferentes modos de referência. Sua questão é "como reproduzimos (ou não) os modos de subjetividade dominante" (GUATTARI; ROLNIK,1986, p. 133) e, deste modo, como validamos ou não as funções de singularização nestes processos que se intitulam transformadores.

Uma micropolítica faz-se imprescindível porque, por exemplo, em um nível molar, um grupo pode se constituir como uma referência política em relação às questões socioambientais, evidenciando modos de singularização em suas práticas, mas, em um nível molecular, estabelecer relações de exploração e dominação entre os membros da instituição ou ainda ao nível interinstitucional, manifestar práticas de extrema competitividade, referentes a registros de modelização dominantes. Um modo de referência engendrando outro ou outros, baseados em múltiplas referências. Vimos estes processos acontecerem dentro do próprio governo popular do Partido dos Trabalhadores, na política cotidiana de seus megaempreendimentos, como, por exemplo, a obra de Belo Monte (PA), que promoveu impactos socioambientais inimagináveis para o Meio Ambiente e para os povos indígenas e ribeirinhos moradores da região. Sobre isso, Guattari irá dizer:

A ação militante também está exposta a riscos de modelização: a "alternativa", por exemplo, pode ser uma modelização igualmente opressora, mas de uma outra forma. Então, uma micropolítica analítica das singularidades teria que atravessar essas diferentes estratificações, esses diferentes níveis (GUATTARI; ROLNIK, 1986, p. 130).

Godoy (2008, p. 59), em seu livro, traz o conceito "menor" para o campo da Ecologia, assumindo o risco de transportá-lo do campo literário para o um científico. A questão se traduz no nome de sua obra, "A menor das ecologias" e nas duas questões que perseguem seu conteúdo: "Que vida a ecologia produz?" e "Que ecologias a vida produz?" (GODOY, 2008, p. 66). Nas entrelinhas das duas questões configura-se um embate entre uma "maior" e uma "menor" ecologia, entre uma modelização e uma 
singularização, entre a fábrica e o ateliê. A primeira enfatiza um projeto prescritivo, em que a ecologia aparece como portadora de uma verdade, da verdade do mundo, a verdade da "descoberta do fundamento da natureza" (GODOY, 2008, p. 59) e, em nome de uma ameaça das forças de conservação da vida, tende a postular modelos e soluções para os problemas que a vida atravessa. A segunda, que se constrói a partir de outra lógica e não apenas de outros conceitos, afirma "a vida como produtora de desvios, de valor, como potência avaliadora e ativa" (GODOY, 2008, p.65). Ao invés de resoluções satisfatórias para a vida, a "potência de pensar e agir são levadas ao limite em vez de meramente encontrarem uma resolução satisfatória (GODOY, 2008, p. 62).

Para a autora, a "maior das ecologias" tem se revelado, sobretudo, em seu projeto conservacionista, de conservação da vida, da casa e dos seres. Em contraposição, "a grandeza do menor estaria nisto que se poderia chamar de não-pertencimento a um modelo" (GODOY, 2008, p. 58) e, sobretudo, ao fato de que as forças da vida não podem ser reduzidas apenas ao que existe e pretende ser conservado.

Um novo tipo ou modo de se fazer política, seja ambiental, seja social, seja econômica, que se paute por princípios socialistas ou sustentáveis, de preferência democrática, não pode ser tecida sem um novo tipo de análise, sem uma micropolítica, sem uma cartografia dos itinerários do desejo no cotidiano, sem um outro tipo de prática, sem um outro tipo de consciência e lógica, sem um outro tipo de sensibilidade, sem uma outra discursividade, sem uma epistemologia complexa, que inclua o ser humano, as subjetividades, o inconsciente e o desejo - que foram recalcados -, nos entrecruzamentos a serem transformados, produzindo modos de singularização, potentes e autônomos, capazes de criarem e se recriarem, a um só tempo.

\section{A Subjetividade como Ateliê em seus Modos de Singularização}

Modos de singularização - esta é a proposta de Guattari e Rolnik -, para contrapor esta máquina capitalística ${ }^{6}$, que seria a expressão de um protesto do inconsciente, na forma de uma recusa:

[...] uma maneira de recusar todos esses modos de encodificação preestabelecidos, todos esses modos de manipulação e telecomando, recusá-los para construir, de certa forma, modos de sensibilidade, modos de relação com o outro, modos de produção, modos de criatividade que produzam uma subjetividade singular. Uma singularização existencial que coincida com um desejo, com um gosto de viver, com uma vontade de construir o mundo no qual nos encontramos, com a instauração de dispositivos para mudar os tipos de sociedade, os tipos de valores que não são os nossos (GUATTARI; ROLNIK, 1986, p. 17).

Um dos fatores mais importantes à emergência destes modos de singularização seria o exercício permanente e cotidiano da criação de novos e próprios modos de referência, de produção de sentido, num nível micropolítico, já que o sistema capitalístico em questão, por exemplo, soube criar sistemas de referências dominantes - afetivas, teóricas, segregadoras, produtivas, entre outras -, que cooptam e recuperam tudo o que é do "domínio da ruptura, da surpresa, da angústia, mas também do desejo, da vontade de amar e de criar" (GUATTARI; ROLNIK,1986, p. 43), trazendo a estes processos sempre algo de "precário e de frágil" (GUATTARI; ROLNIK,1986, p. 53).

Para os autores, a criação de modos de singularização não se dá na polarização entre formas de denúncia e/ou de resistência, mas "investindo em seu próprio coração", promovendo um jogo "que a revela e a faz desmoronar". Isto se dá através da produção e da invenção de "subjetividades delirantes"; da "frustração dos processos maquínicos"; da "afirmação dos valores numa esfera particular"; na "multiplicidade de processos de semiotização"; na "reapropriação de dimensões essenciais da existência,

\footnotetext{
${ }^{6}$ É um conceito de Félix Guattari que se refere aos processos de subjetivação próprios não apenas das sociedades capitalistas, mas dos setores chamado Terceiro Mundo, capitalismo periférico e das sociedades socialistas de outrora que, em se tratando do modo de produção de subjetividade, em nada se diferenciavam, por funcionarem segundo uma mesma cartografia do desejo no campo social e uma economia política (GUATTARI; ROLNIK, 1986, p.15).
} 
como o desejo, a angústia, a morte, a dor, a solidão, o silêncio, a relação com o cosmos, com o tempo", processos invisibilizados, porque promovem uma verticalidade na singularidade; na reinvenção dos modos de trabalho e produção, de ensino e aprendizagem, em formas de produção de sentido e de práxis. Tal projeto, muito mais ousado que uma mera resistência, caracteriza-se por uma produção, nos moldes das pulsões do inconsciente, de "máquinas de guerra", capazes de promover "revoluções moleculares".

Importa-nos, ter sempre em mente, em nossos processos analíticos, quais são as formas de modelização e processos de subjetivação hegemônica que resistem e nos capturam, assim com vasculhar cuidadosamente os nossos discursos para perceber se e onde guardam resquícios das instâncias de culpabilização, segregação e infantilização. Finalmente, precisamos abrir espaço e tempo para a invenção e a criação de novas formas de nos relacionar, de pensar, de falar, de escrever, de produzir saberes e práticas inusitadas, de sentir e de produzir sentido - que escapem aos modelos aprendidos e validados numa experiência que se pauta no passado e na histórica, como critérios de legitimidade. E aí a pergunta que precisa ser feita é: que espaço-tempo têm sido dados para se repensar os processos, entendidos quase como dados e não construtos, que clamam por novas configurações, como os processos políticos, os processos relacionais, os processos éticos, os processos humanos e os processos ecológicos, mas que continuam a ser referidos como ideais?

Para que não percamos a potência de tal pergunta, apropriando-a com respostas prévias, precisamos mantê-la como questão que reverbera e precisa reverberar por algum tempo. Outra forma potente de lidar com ela é afirmarmos que não sabemos. O "não saber" é mais potente que o pseudo saber. Entre o não saber e a busca de um outro saber, encontramos as experiências da vida, no meio, como possibilidades. É sobre esta tentativa que se refere o fragmento a seguir.

\section{A Subjetividade em seus Modos de Singularização e o Projeto Social Filhos da Terra (Arte- educação, Cidadania e Ecologia): experiência da práxis}

Imagem 01 - Caravana da Alegria - a vida como celebração (Fabiano Bittencourt).

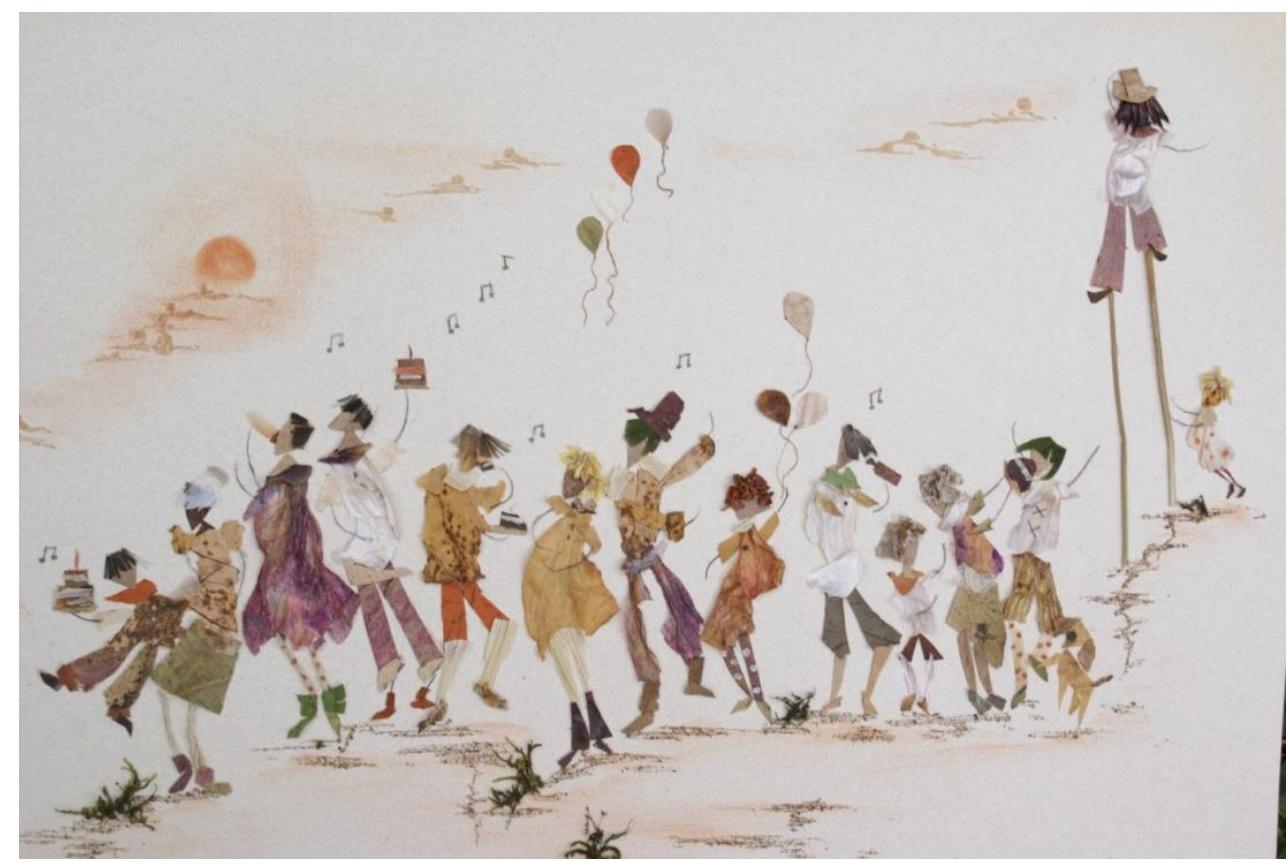

Fonte: Catálogo da Exposição Eco-artesanal Filhos da Terra, 2008.

Inicio esta reflexão chamando a atenção sobre o quadro acima, do jovem artista Fabiano Bittencourt, intitulado "Caravana da Alegria - A Vida como Celebração". Este quadro fez parte de um acervo, de 48 obras, exposto no Centro Cultural da Caixa Econômica, em São Paulo, em novembro de 2008. Da periferia de uma grande cidade, estes jovens tornaram-se artistas, através de uma experiência em um Projeto Social, onde fui coordenadora, na Cidade de Petrópolis (RJ), nomeado por eles, como 
Filhos da Terra. Idealizado em uma Organização de Direitos Humanos, os "Filhos da Terra", constituíramse, apoiados nos princípios propostos pela política de cultura, do Ministério da Cultura do governo do Partido dos Trabalhadores: conceber a arte como dimensão simbólica, cidadã e econômica.

Estes jovens passaram mais de uma década buscando conjugar arte, cidadania, ecologia e sustentabilidade econômica, através de um educação pautada em modos de singularização. Além de estarem envolvidos na escrita e no fazer teatral, tais jovens desenvolveram, inspirados em uma artista capixaba, Dida Thomé, a arte apenas com os elementos disponibilizados pela natureza: areias coloridas, pétalas de folhas caídas, cascas, conchinhas, fiapos de penas de pássaros, conchinhas, sementes diversas, gavinhas, bambus, papel reciclado. A singularização manifestou-se nos distintos talentos artísticos, especialmente expostos na Exposição Eco-Artesanal Filhos da Terra, no Centro Cultural da Caixa Econômica, em São Paulo, intitulada "Filhos da Terra: a sutil arte de conjugar ecologia, solidariedade e consciência social". Entre muitos cenários do cotidiano empobrecido, de onde vieram, uma artista se consagrou por criar obras a partir da cultura popular; outra artista passou a criar mandalas; outra, a ilustrar os vários cenários cotidianos da favela; outro, tornou-se um artista de santos e santas. Todos se tornaram educadores populares, monitores de Oficinas de Sensibilização Ecológica, ministradas em muitos lugares e instituições, inclusive entre alguns presos da Penitenciária Estadual do Paraná.

Entre muitas obras, gostaria de dizer algo sobre a obra acima destacada. Nela, Fabiano consegue retratar a proposta do próprio grupo e que nos remete à experiência da arte como processo de singularização. Foi uma das primeiras obras a serem adquiridas na exposição. A cena do quadro referese a uma Caravana, grupo de viajantes, andarilhos e peregrinos, que se agrupam para realizarem, juntos, uma viagem ou uma trajetória. Todos são diferentes e codividem uma mesma caravana. Implica em um deslocamento e em um movimento. Mas esta não é qualquer caravana. $O$ autor a qualifica: é uma caravana da alegria! Nem precisava dizer. Os personagens nos narram esta qualidade. Há muita música na cena, bolas de gás ao vento, o que sugere uma festa; os personagens mostram-se em movimento, como se participassem de uma dança. Alguns pulam. Há mulheres, homens, negros, brancos, pobres, ricos, crianças, artistas, e um cachorro. O homem sobre as pernas de pau nos faz lembrar a arte circense. Algumas pessoas bebem, parecem se embriagar. Uma delas dá de beber a outra pessoa. E três pessoas seguram bolos, com velas acesas, sugerindo uma festa. Um deles está degustando uma fatia do bolo. Uma mulher carrega lindamente a sua criança. Interessante perceber que embora a caravana esteja em movimento, o cenário não sugere direção. Não há linearidade nesta caravana. Não sabemos em que direção ela avança. Não sabemos se é noite ou se é dia, mas sabemos que estão num caminho de terra, como os terreiros das casas do interior, que abrigam uma multiplicidade de pessoas em seus festejos.

Na obra de Fabiano há um subtítulo: "a vida como celebração". A vida pode ser e é uma infinidade de perspectivas. Mas a perspectiva apontada aqui é a da celebração. Celebramos aquilo que nos importa. Criamos ritos de passagens para marcar esta diversidade de momentos.

Este Projeto, desde o seu desenho inicial e coletivo, acreditou na importância de uma arte por si mesma e de uma noção filosófica da arte, para além de uma técnica. Arte como uma forma de conduzir a existência em um processo de criação e invenção permanentes, do mundo e de si, através de múltiplas lógicas e linguagens. Arte como um espírito que nos autoriza a conceber a vida mais como um processo de abertura, de invenção e construção permanentes, do que como obra de arte acabada, passível apenas de aprendizado e contemplação. Todas as inspirações e concepções convergem para o compromisso com os modos de singularização.

Por ser um projeto social, sempre fomos interpelados se a arte não deveria ser instrumento político dos ideários de emancipação e transformação, de forma mais intencional e explícita. E sempre resistimos a esta forma de didatização dos processos, que os transformam em meio para outros fins e que corroboram com processos de subjetivação.

Idealizado em forma de Oficinas, a arte e a educação fizeram parte do transfundo de tal experiência social e socioambiental. Mais do que fundo, da própria atmosfera na qual nossas existências se inserem para viver. Não pensamos em uma Educação Ambiental que fosse tema ou oficinas próprias, mas o fio condutor de todos os temas e oficinas. O ambiental sempre teve mais a ver com uma forma outra se conceber no ambiente e nas inter-retro-relações do mesmo, do que num tema específico. Uma forma 
artística de trabalhar a educação ambiental com jovens, comprometendo-nos com os modos de singularização.

Sim, uma Educação Ambiental que se constrói como ateliê nos espaços singulares de vida e que se compromete com subjetividades em criação (processos de singularização) não é a mesma que se constitui como fábrica e produz ideários: de mundo, de ser humano, de percurso, de discursividade, de valores, de consciência e de ação, ainda que seja em nome de um projeto de vida. Somente os sujeitos coletivos, singularizados, darão conta de sustentar outras formas de estar, de viver e de se relacionar com o mundo e as pessoas. Os jovens deste projeto, hoje adultos, que se formaram bailarinos, psicólogos, biólogos, escultores, pintores, artistas de circo e de teatro encantam o mundo em suas caravanas, no Brasil e no exterior, por aí afora, em tramas sem fim.

\section{REFERÊNCIAS}

CATÁLOGO DA EXPOSIÇÃO ECO-ARTESANAL FILHOS DA TERRA. Curadoria de Maristela Barenco Corrêa de Mello. Centro de Defesa dos Direitos Humanos e Caixa Cultural, São Paulo, 2008.

DELEUZE, Gilles. Nietzsche e a Filosofia. Rio de Janeiro: Editora Rio, 1976. Disponível em: <http://www.casadosino.com.br/divulgacao/biblioteca/deleuze_nietzsche_ea_filosofia.pdf >. Acesso em: 08 dez. 2010.

FOUCAULT, Michel. História da Sexualidade 3: o cuidado de si. 10. reimp. Rio de Janeiro: Edições Graal, 2009. $246 \mathrm{p}$.

FREIRE, Paulo. Pedagogia do Oprimido. 13. ed. Rio de Janeiro: Paz e Terra, 1983. 218 p.

GUATARRI, Félix; ROLNIK, Suely. Micropolítica: Cartografias do Desejo. 2. ed. Petrópolis: Vozes, $2^{a}$ edição, 1986. $323 \mathrm{p}$.

GODOY, A. A Menor das Ecologias. São Paulo: Edusp, 2008, 333 p.

GRÜN, Mauro. Ética e Educação Ambiental: A conexão necessária. 10. ed. São Paulo: Papirus, 2006. 120 p.

LOUREIRO, Carlos Frederico Bernardo; LAYRARGUES, Philippe Pomier; CASTRO, Ronaldo Souza de (Orgs.). Educação Ambiental: repensando o espaço da cidadania. São Paulo: Cortez, 2002. 206 p.

MELLO, Maristela Barenco Corrêa de. Da morte do General à busca rizomática: a escrita como possibilidade de emancipação. Agenciamentos entre Cora Coralina, Gilles Deleuze e Félix Guattari. Dissertação (Mestrado em Educação) - Programa de Pós-Graduação em Educação/ ProPEd, Universidade do Estado do Rio de Janeiro, Rio de Janeiro, 2005.

- Anotações esparsas sobre subjetividade. In: NEFFA, Elza; RITTO, Antonio C. (Orgs.). Percepção Transdisciplinar: uma construção coletiva. Rio de Janeiro: EdUerj, 2010. p. 43-60.

. Projeto Florescer: Arte-Educação, Cidadania e Ecologia. Uma Metodologia para trabalhar com jovens. Petrópolis: Centro de Defesa dos Direitos Humanos de Petrópolis, 2010. 95 p.

. Uma Educação Ambiental como Estética da Existência e Epistemologia dos Nexos. A experiência sócio-educativa do Projeto Florescer. Tese (Doutorado em Meio Ambiente) - Programa de Pós-Graduação em Meio Ambiente/ PPGMA, Universidade do Estado do Rio de Janeiro, Rio de Janeiro, 2011.

Recebido em: 15/09/2018

Alterações recebidas em: 16/11/2018

Aceito em: 16/11/2018 